\title{
The Relationship between Alcohol and Seizures: An Overview of the Major Data
}

\section{Hélène Visée*}

Neurological department, University Hospital Center-Brugmann, Brussels, Belgium

\begin{abstract}
Harmful use of alcohol is associated with a higher risk of seizures. The relationship between alcohol and seizures is complex. Numerous researches on rats and mice have contributed to elucidate alcohol's effects on the brain. The consequences of seizures are relevant in terms of quality of life, injuries, therapeutical adherence, social and professional insertion. Therefore, it is important for all patients, whatever their age or stage of the alcoholism intoxication process (from first experience to chronical alcoholism) to tent to prevent the apparition of seizures, providing adequate prevention of withdrawal syndrome and to identify the patients who need chronic antiepileptic treatment. This presentation summarizes some of major data to understand how alcohol consumption, from acute intoxication to chronic misuse, can promote seizures and the basic measures to manage alcohol-related epilepsy.
\end{abstract}

Keywords: Alcohol; Seizures; Alcohol withdrawal seizures; Alcoholrelated seizures

\section{Introduction}

Ethanol is an old recreational and social beverage easily obtained by fermentation of sugars and consumed throughout the world. The highest level of consumption is observed in developed countries [1]. The harmful use of alcohol, defined as a pattern of drinking that leads to physical or mental damage, is recognized by the World Health Organization as one of the major risk factors for the development of disease, disabilities and death throughout the world [1]. It has also been associated with an increased risk of seizures. A meta-analysis performed in 2010 by Samokhvalov and coworkers concludes to a relative risk (RR) for epilepsy/unprovoked seizures of 2.19 (95\% confidence interval $\mathrm{CI}=1.83-2.63$ ) for alcohol consumers, compared to abstainers. These authors point out a dose-response relationship between the daily amount of alcohol intake and the RR of epilepsy, raising from $1.17(95 \% \mathrm{CI}=1.13-1.21)$ to $3.27(95 \% \mathrm{CI}=2.52-4.26)$ for an individual daily alcohol consumption of $12 \mathrm{~g}$ to $96 \mathrm{~g}$ respectively [2]. It is likewise observed, in a multicenter case-control study performed in Italy, that an alcohol intake of more than $\mathbf{5 0}$ grams a day is a risk factor (odds ratio 4.9; confidence limits 3.1-7.9) for a first generalized tonicoclonic seizure in adult life ( $\geq 15$ years) [3].

The relationship between alcohol and seizure/epilepsy is complex. On the one hand, ethanol misuse promotes the occurrence of brain diseases or metabolic changes that can provoke seizure (such as stroke, traumatic brain injuries, dementia and acute hyponatremia). On the other hand, the toxicity of ethanol changes neurotransmitter pathways modifying the epileptic threshold. The risk for alcohol-related seizures depends on the daily amount of alcohol intake but is also modulated by multiple individual factors as sex, age, genetic factors, environmental factors and co-morbidities. Psychiatric co morbidities associated with alcohol misuse can also aggravate neurological status or diminish the epileptic threshold (e.g., depression and anxiety disorders leading to neuroleptic or antidepressant drugs use).

Although epilepsy is a common disease around the world, it remains often misunderstood by some or stigmatized, can deteriorate social integration or self-esteem and can promote psychiatric comorbidities as depression, anxiety and suicide [4]. The risk of injuries and cognitive deterioration related to epilepsy adds to these related directly to alcohol, with possible loss of autonomy as consequences. Hence, it is important to tent to prevent the apparition of epilepsy in the context of alcohol misuse, essentially providing adequate withdrawal management, or to treat it adequately once necessary. This presentation provides an overview of the major data about the relationship between alcohol consumption and seizures/epilepsy and the management of alcoholrelated seizures.

\section{Alcohol and Central Nervous System, from Acute Alcohol Intoxication to Alcohol Tolerance}

A little part (up to 10\%) of the ingested alcohol is eliminated through the lungs, urine and sweat. The main part is metabolized by the stomach and the liver. Afterwards, the remaining amount of ethanol and its metabolite acetaldehyde crosses the blood brain barrier and affects brain neurotransmitters. The main signs of acute intoxication are dose-dependant and consist of behavioral (euphoria, anxiolysis, disinhibition) and cognitive (misjudgment and memory problems) changes, as well as altered states of consciousness, ranging from slight sedation to coma. Due to prolonged alcohol exposition, the central nervous system adapts and develops alcohol tolerance, defined as the need to drink more alcohol to obtain signs of intoxication or the desired effect [5].

Several variants of alcohol dehydrogenase $(\mathrm{ADH})$ and aldehyde dehydrogenase $(\mathrm{ALDH})$, two enzymes implicated in the peripheral alcohol metabolism and a wide polymorphism among genes implicated in neurotransmitter pathways contribute to the variability of the individual alcohol sensitivity and the risk of alcohol-use disorders [6]. The term alcohol-use disorders make reference to alcohol abuse (a maladaptive pattern of substance use leading to clinically significant impairment or distress [...]), and alcohol dependence (physiological dependence on alcohol is indicated by evidence of tolerance or symptoms of withdrawal) [5].

Numerous ethanol brain targets have been identified. The part

*Corresponding author: Hélène Visée, University Hospital Center-Brugmann Neurology department, Place Van Gehuchten 4, 1020 Brussels, Belgium, Tel: 00 32247737 60, Fax: 0032247734 67; E-mail: Helene.visee@chu-brugmann.be

Received October 14, 2014; Accepted January 20, 2015; Published January 30, 2015

Citation: Visée H (2015) The Relationship between Alcohol and Seizures: An Overview of the Major Data. Int J Neurorehabilitation 2: 141. doi:10.4172/23760281.1000141

Copyright: () 2015 Visée $\mathrm{H}$. This is an open-access article distributed under the terms of the Creative Commons Attribution License, which permits unrestricted use, distribution, and reproduction in any medium, provided the original author and source are credited. 
of each in the apparition of alcohol-use disorders or alcohol-related seizures is still the subject of several researches. Among them, the glutamatergic N-methyl-D-aspartate (NMDA) receptor is one of the major keys for a better understanding of the relationship between alcohol and seizures.

The amino acid glutamate belongs to a complex system involved in fast synaptic transmission, plasticity and cognitive/memory functions. It is known as the major excitatory neurotransmitter used throughout the brain. The glutamatergic post-synaptic action is mediated by ionotropic receptors (ligand-gate ion channels, represented by NMDA, kainic acid (KA) and a-amino-3-hydroxy-5-methyl-4-isoxazole (AMPA) receptors) and metabotropic receptors (G protein-mediated receptors). The ionotropic NMDA receptor is formed by a combination of two subunits. One (NR1) determines the major electrophysiological and pharmacological features of the NMDA receptor, while the other (NR2) confers modulatory properties. Both subunits present several variants (respectively seven and four). The first is expressed at high levels in most neurons, while the expression of the other evolves from the developing into the adult brain [7].

Various researches on mouse and rat brains or cultured cells have demonstrated an inhibition of the NMDA receptor activity induced by acute alcohol ingestion [8-11]. Lovering and coworkers have demonstrated a linear inhibition up to $61 \%$ of the ion current produced by NMDA receptors, induced by ethanol (from 5 to $50 \mathrm{mM}$ ), and a slighter ethanol affinity to inhibit the AMPA and KA receptor function [12]. Several allosteric regulatory binding sites on the NMDA receptor modulate its activity (such as the binding site of glycine). It can also vary according to the subunits composition of the receptor, which varies across brain regions $[7,13]$.

Contrariwise, ethanol facilitates the activation of $\gamma$-amino butyric acid (GABA)a receptor [14], a chloride channel that stabilizes the membrane potential near the resting level. This effect is variably highlighted, maybe due to an indirect effect of ethanol to the GABA receptor [15] or due to the variation of subunit composition [13].

In acute alcohol intoxication, the inhibition of the NMDA receptor combined to the enhancement of the GABAa activity offer clues to understand dose-related clinical signs of acute intoxication, during which the epileptic threshold is raised.

\section{Alcohol and Central Nervous System, from Chronic Alcohol Intoxication to Alcohol-Dependence and Withdrawal Syndrome}

According to the definition of the DSM-IV, physiological dependence on alcohol is indicated by evidence of alcohol tolerance or symptoms of alcohol withdrawal including withdrawal seizures [5].

It is observed in rats that chronic ethanol administration induces up-regulation of the glutamate receptors with a raised amount of subunits NR1, NR2A and 2B in the cortex and hippocampus. This phenomenon is reversible and returns almost to baseline $48 \mathrm{~h}$ after the last dose of ethanol administration [16]. In rat experiments, the overexpression of NMDA receptors leads to glutamatergic hyperactivity in the hours after alcohol withdrawal and the release of the NMDA receptor inhibition $[11,17]$. This hyperactivity is temporally correlated with the withdrawal symptoms. Furthermore, the administration of a NMDA receptor antagonist reduces ethanol withdrawal symptoms and glutamate extracellular overflow, in the same way that ethanol recharges, whereas diazepam reduces withdrawal symptoms but not glutamatergic output [17].
A similar mechanism is observed with the L-type voltage-sensitive calcium channels, which are inhibited by acute exposition to ethanol and up-regulated after chronic exposition. They can contribute to the further withdrawal syndrome [13]. Moreover, the chronic exposition to alcohol decreases the expression of $\alpha 1$ and $\alpha 2$ mRNAs subunits of the GABAa receptor in the brain cortex of rats [18], a mechanism that is probably also implicated in tolerance phenomena.

Headache, tremor, agitation, anxiety, sweating, craving to drink, but also abnormal vital signs as tachycardia, hypertension, hyperthermia, and tachypnea can be the first symptoms of alcohol withdrawal. Fast intervention is needed to prevent further severe complications as seizure, delirium tremens or sever autonomic hyperactivity. The mortality related to alcohol withdrawal syndrome reaches about $8 \%$ [19]. Generalized tonic-clonic seizures occur in 3 to $10 \%$ of individuals in alcohol withdrawal $[5,20]$. Focal seizures related to alcohol consumption are also reported (up to $24 \%$ in the alcohol related seizures group reported by Earnest and Yarnell) with an other underlying etiology in some of them (up to $15 \%$ in the same series) [21-23].

Using benzodiazepines (BZD) for seven days is recommended to prevent the withdrawal syndrome when a detoxification is planned for a patient who has at least one of the following: 1) a daily consumption reaching 10 units in woman or 15units in men ( 1 unit $=$ a beverage containing $8 \mathrm{~g}$ of ethanol). 2) recent withdrawal symptoms. 3) recent drinking to prevent withdrawal symptoms. 4) heavy episodic drinking (>20 units/day) with a last bout longer than one week [24]. 5) a history of withdrawal seizures. 6) notable comorbid medical illness [25]. All BZD seems to be efficient to reduce withdrawal symptoms. The use of long-acting agents (as diazepam and chlordiazepoxide) presents the risk of prolonged sedation. Agents with shorter half life (as lorazepam) can be considered as first choice in elderly who present lower metabolism and higher risk of toxic accumulation [25]. Besides, lorazepam has the advantage of a prolonged anticonvulsive activity and reduces the risk of recurrent seizures compared to placebo $[19,26]$ but evidence lacks to make further recommendations [24,27]. The risk of misuse exists with all BZD and their utilization must be supervised [24,25].

In the case of unplanned or spontaneous withdrawal and according to the severity of the latter, oral or intravenous BZD are used as first choice, eventually associated with phenobarbital (PB) or propofol in most severe cases [20]. Indeed, PB enhances both the binding of GABA and the binding of BZD to the GABAa receptors, promoting the BZD effect. Propofol offers probably the advantage of a combined GABAergic and anti-NMDA activity, and has documented effectiveness in BZD resistant withdrawal syndrome [20].

Alcohol-withdrawal seizures occur between 6 at 48 hours after cessation of alcohol consumption in one third of patients in withdrawal status, and can precipitate status epilepticus (up to $10.8 \%$ of the patients admitted for generalized status epilepticus) [28]. BZD are the drugs of choice to treat seizures. They are efficacious and safe for primary and secondary seizure prevention. Lorazepam presents the advantage of long-acting anticonvulsant action, compared to diazepam or midazolam $[29,30]$. Other anticonvulsant drugs associated to BZD should be restricted to the first few days because they do not provide evidence of preventing further withdrawal seizures [27, 31-33] and because of the elevated risk of poor therapeutic compliance in this population [32,33].

Due to the heterogeneity of the trials, three reviews realized respectively in 2005, 2010 and 2011, failed to demonstrate a benefit of anticonvulsant therapy in the prevention/treatment of alcohol withdrawal syndrome $[27,34,35]$. The major points can be resumed 
as follows: valproate and carbamazepine tried in primary prevention and compared with placebo were difficult to use because of rapid titration and related side effects [32]. Phenytoin failed to prevent relapses of alcohol withdrawal seizures as compared to placebo, in a tiny study population [31]. Oxcarbazepine was as efficient as BZD to prevent seizures and reduce withdrawal symptoms and provided the advantages of lower side effects and easier tapering, but again the study population was small [36]. Topiramate, a large spectrum antiepileptic with GABAergic and antiNMDA activities, has demonstrated efficacy to prevent seizures and reduce withdrawal symptoms in rats and mice $[37,38]$ and to prevent seizures (open label study, with only 12 patients) and to improve alcohol dependence in humans $[39,40]$.

Besides pharmacological therapy, cognitive-behavioral therapies should be introduced to modify the attitude towards alcohol, to keep the patient motivated to stay abstinent and to sustain the rehabilitation [41].

\section{From First Withdrawal Seizure to Epilepsy}

It is observed that withdrawal symptoms become more severe after repeated episodes $[42,43]$. Sandeep and coworkers report a significant association between cortical atrophy and duration of alcohol intake (mean duration of 23.62years, in a population study of 100 patients) with a higher risk of clustering seizures in this group [23].

It is also observed that spontaneous seizures (i.e. not related to withdrawal episode) can occur later in life in alcoholic patients. Bartolomei and coworkers, observed that alcoholic patients presenting spontaneous seizures are older, present a longer duration of intoxication, have more often brain atrophy, a history of higher number of previous seizures, and more neurologic signs, compared with alcoholic patient presenting withdrawal seizures only [44]. The apparition of spontaneous seizures and epilepsy, defined by the International League Against Epilepsy as a disease of the brain generating at least two unprovoked seizures occurring $>24 \mathrm{~h}$ apart [45], requires the instauration of longterm antiepileptic drugs (AED) and the avoidance of alcohol withdrawal episodes. It is estimated that the duration of heavy alcohol consumption must reach a dozen years to produce repetitive unprovoked seizures $[2,44]$.

The choice of AED will be guided by the side effects profile: older AED's as valproate, phenytoin and carbamazepine present higher risks of drug-drug interactions, hepatotoxicity, pancreatitis and in case of valproate- hepatic encephalopathy. Among newer AED: topiramate seems to present advantages to reduce alcohol-dependence [37-40], whereas levetiracetam failed [46]. Gabapentine needs more investigations to confirm a quite similar benefit, observed in rats but not in heavy drinking humans $[47,48]$.

\section{Alcohol-Related Seizures with another Underlying Etiology}

In a retrospective study of 140 patients presenting alcohol related seizures, Rathlev et al identified a potential other etiology of seizure in $53.6 \%$ of them (acute or past history of significant head trauma, idiopathic seizure disorder, stroke, non-traumatic intracranial lesion, toxic-metabolic abnormalities) [49]. Brain imaging and electroencephalography (EEG) should be performed after the first episode of alcohol withdrawal seizure. It should be repeated in case of focal seizures [23].

Furthermore, all alcohol related seizures are not related to alcoholism. It is well known that acute alcohol intake, even at low dose, can provoke myoclonic or generalized seizures in genetically determined epilepsy syndromes such as juvenile myoclonic epilepsy and epilepsy with generalized tonic clonic seizures only. These patients must be well informed of the risk of ethanol consumption (in particular in association with sleep deprivation). Avoidance of precipitant seizure factors is one of the major parts of their treatment. An profound anamnesis, in search of previous seizures, absences of myoclonia, combined to EEG investigations are recommended for all patients to identify those with underlying genetic determined epilepsy, especially among patient with seizures within 6 hours after intake of alcohol without withdrawal symptoms [23].

\section{Alcohol and Aging}

The nature of the risks related to alcohol consumption varies during life. Due to the immature state of their brain, people exposed to alcohol early in life present a risk factor for alcohol misuse in later life $[1,50]$. Children, adolescents and also elderly are more vulnerable to alcohol-related injuries and crashes with motor-vehicles [1], whereas mild to severe traumatic brain injuries increase the risk of epilepsy and are incriminated in about $6 \%$ of epilepsy [51]. Among the elderly, alcohol misuse concerns $1-3 \%$ of them and is sometimes underestimated [52]. Elderly are susceptible to present more severe and longer alcohol withdrawal symptoms than mid-life adults [53]. Some particularities appear with aging: the gastric and liver metabolism of alcohol is reduced, enhancing the blood level of ethanol and its impact on the central nervous system, the epileptic threshold decreases and the incidence of both convulsive and nonconvulsive status epilepticus raises after the age of 60 years [54]. By these ways, the elderly population is particularly vulnerable to alcohol misuse and its consequences.

\section{Conclusions}

The management of alcohol-related seizures should not be underestimated, whatever being the patient's age. Repetitive withdrawal syndrome should be avoided to lower the risk of further development of epilepsy. A systematic screening of drinking habits, equally in elderly, could therefore be helpful. Adequate anamnesis, radiological and EEG investigations should be performed to identify patients who should benefit of a prolonged AED treatment.

\section{References}

1. World Health Organization. Global status report on alcohol and health 2014 ISBN 9789240692763 (PDF)

2. Samokhvalov AV, Irving H, Mohapatra S, Rehm J (2010) Alcohol consumption, unprovoked seizures, and epilepsy: a systematic review and meta-analysis. Epilepsia 51: 1177-1184.

3. M Leone, E Bottacchi, E Beghi, E Morgando, R Mutani, R Cremo. Risk factors for a first generalized tonic-clonic seizure in adult life. Neurol Sci 2002;23:99106

4. Verrotti A, Carrozzino D2, Milioni M3, Minna M2, Fulcheri M4 (2014) Epilepsy and its main psychiatric comorbidities in adults and children. J Neurol Sci 343: 23-29.

5. Pitcher TM, Piek JP, Barrett NC (2002) Timing and force control in boys with attention deficit hyperactivity disorder: subtype differences and the effect of comorbid developmental coordination disorder. Hum Mov Sci 21: 919-945.

6. Morozova TV, Mackay TF, Anholt RR (2014) Genetics and genomics of alcohol sensitivity. Mol Genet Genomics 289: 253-269.

7. Cotman CW, Kahle JS, Miller SE, Ulas J, Bridges RJ (1995) Excitatory Amino Acid Neurotransmission. (1995) In : Psychophramacology. The Fourth Generation of Progress, 75-85. Edited by Bloom,F.E. and Kupfer, D.J. New York, Raven Press

8. Bhave SV, Snell LD, Tabakoff B, Hoffman PL (1996) Mechanism of ethanol inhibition of NMDA receptor function in primary cultures of cerebral cortical cells. Alcohol Clin Exp Res 20: 934-941. 
Citation: Visée H (2015) The Relationship between Alcohol and Seizures: An Overview of the Major Data. Int J Neurorehabilitation 2: 141. doi:10.4172/2376-0281.1000141

9. Hoffman PL, Bhave SV, Kumar KN, lorio KR, Snell LD, et al. (1996) The 71 kDa glutamate-binding protein is increased in cerebellar granule cells after chronic ethanol treatment. Brain Res Mol Brain Res 39: 167-176

10. Snell LD, Nunley KR, Lickteig RL, Browning MD, Tabakoff B, et al. (1996) Regional and subunit specific changes in NMDA receptor mRNA and immunoreactivity in mouse brain following chronic ethanol ingestion. Brain Res Mol Brain Res 40: 71-78.

11. Rossetti ZL, Carboni S, Fadda F (1999) Glutamate-induced increase of extracellular glutamate through $\mathrm{N}$-methyl-D-aspartate receptors in ethanol withdrawal. Neuroscience 93: 1135-1140.

12. Lovinger DM, White G, Weight FF (1989) Ethanol inhibits NMDA-activated ion current in hippocampal neurons. Science 243: 1721-1724.

13. Krystal JH, Tabakoff B (2002) Ethanol abuse, dependence, and withdrawal: neurobiology and clinical complications. In: Neuropsychopharmacology: The Fifth Generation of progress, 1425-1443. Edited by Davis K.L., Charney D, Coyle J.T., and Nemeroff C. Lippincott Williams and Wilkins.

14. Harris RA, Allan AM (1985) Functional coupling of gamma-aminobutyric acid receptors to chloride channels in brain membranes. Science 228: 1108-1110.

15. Olsen R.W (2002) In: Neuropsychopharmacology: The Fifth Generation of progress, 159-168. Edited by Davis K.L., Charney D, Coyle J.T., and Nemeroff C. Lippincott Williams and Wilkins.

16. Kalluri HS, Mehta AK, Ticku MK (1998) Up-regulation of NMDA receptor subunits in rat brain following chronic ethanol treatment. Brain Res Mol Brain Res 58: 221-224.

17. Rossetti ZL, Carboni S (1995) Ethanol withdrawal is associated with increased extracellular glutamate in the rat striatum. Eur J Pharmacol 283: 177-183.

18. Montpied P, Morrow AL, Karanian JW, Ginns El, Martin BM, et al. (1991) Prolonged ethanol inhalation decreases gamma-aminobutyric acidA receptor alpha subunit mRNAs in the rat cerebral cortex. Mol Pharmacol 39: 157-163.

19. Kattimani S, Bharadwaj B1 (2013) Clinical management of alcohol withdrawal: A systematic review. Ind Psychiatry J 22: 100-108.

20. Stehman CR, Mycyk MB (2013) A rational approach to the treatment of alcoho withdrawal in the ED. Am J Emerg Med 31: 734-742.

21. Earnest MP, Yarnell PR (1976) Seizure admissions to a city hospital: the role of alcohol. Epilepsia 17: 387-393.

22. Hillbom ME (1980) Occurrence of cerebral seizures provoked by alcohol abuse. Epilepsia 21: 459-466.

23. Sandeep P1, Cherian A, lype T, Chitra P, Suresh MK, et al. (2013) Clinica profile of patients with nascent alcohol related seizures. Ann Indian Acad Neurol 16: 530-533.

24. Scottish Intercollegiate Guidelines Network. Guidelines 74. Management of harmful drinking and alcohol dependence in primary care. 2003, updated 2004.

25. Mayo-Smith M.F (1997) Pharmacological Management of Alcohol Withdrawal Pharmacological Management of Alcohol Withdrawal. A Meta-analysis and Evidence-Based Practice Guideline. JAMA 278: 144-151.

26. D'Onofrio G, Rathlev NK, Ulrich AS, Fish SS, Freedland ES (1999) Lorazepam for the prevention of recurrent seizures related to alcohol. N Engl J Med 340: 915-919.

27. Amato L, Minozzi S, Davoli M (2011) Efficacy and safety of pharmacological interventions for the treatment of the Alcohol Withdrawal Syndrome. Cochrane Database Syst Rev : CD008537.

28. Alldredge BK, Lowenstein DH (1993) Status epilepticus related to alcoho abuse. Epilepsia 34: 1033-1037.

29. Bråthen G, Ben-Menachem E, Brodtkorb E, Galvin R, Garcia-Monco JC, et al. (2005) EFNS guideline on the diagnosis and management of alcohol-related seizures: report of an EFNS task force. Eur J Neurol 12: 575-581.

30. Ntais C, Pakos E, Kyzas P, loannidis JP (2005) Benzodiazepines for alcoho withdrawal. Cochrane Database Syst Rev : CD005063.

31. Alldredge BK, Lowenstein DH, Simon RP (1989) Placebo-controlled trial of intravenous diphenylhydantoin for short-term treatment of alcohol withdrawal seizures. Am J Med 87: 645-648.

32. Hillbom M, Tokola R, Kuusela V, Kärkkäinen P, Källi-Lemma L, et al. (1989) Prevention of alcohol withdrawal seizures with carbamazepine and valproic acid. Alcohol 6: 223-226.
33. Leach JP, Mohanraj R, Borland W (2012) Alcohol and drugs in epilepsy: pathophysiology, presentation, possibilities, and prevention. Epilepsia 53 Supp 4: 48-57.

34. Polycarpou A, Papanikolaou P, loannidis JP, Contopoulos-loannidis DG (2005) Anticonvulsants for alcohol withdrawal. Cochrane Database Syst Rev : CD005064.

35. Minozzi S, Amato L, Vecchi S, Davoli M (2010) Anticonvulsants for alcohol withdrawal. Cochrane Database Syst Rev 17: CD005064.

36. Ponce G, Rodríguez-Jiménez R, Ortiz H, Rubio G, Jiménez-Arriero MA, et al. (2005) [Oxcarbazepine in the prevention of epileptic syndromes in alcohol detoxification]. Rev Neurol 40: 577-580.

37. Cagetti E, Baicy KJ, Olsen RW (2004) Topiramate attenuates withdrawal signs after chronic intermittent ethanol in rats. Neuroreport 15: 207-210.

38. Farook JM, Morrell DJ, Lewis B, Littleton JM, Barron S (2007) Topiramate (Topamax) reduces conditioned abstinence behaviours and handling-induced convulsions (HIC) after chronic administration of alcohol in Swiss-Webster mice. Alcohol Alcohol 42: 296-300.

39. Rustembegovic A, Sofic E, Kroyer G (2002) A pilot study of Topiramate (Topamax) in the treatment of tonic-clonic seizures of alcohol withdrawal syndromes. Med Arh 56: 211-212.

40. Johnson BA, Rosenthal N, Capece JA, Wiegand F, Mao L, et al. (2007) Topiramate for Alcoholism Study Group. Topiramate for treating alcohol dependence: a randomized controlled trial. JAMA 298: 1641-1651.

41. Schuckit MA (2009) Alcohol-use disorders. Lancet 373: 492-501.

42. Becker HC (1998) Kindling in alcohol withdrawal. Alcohol Health Res World 22: 25-33.

43. Ballenger JC, Post RM (1978) Kindling as a model for alcohol withdrawal syndromes. Br J Psychiatry 133: 1-14.

44. Bartolomei F, Suchet L, Barrie M, Gastaut JL (1997) Alcoholic epilepsy: a unified and dynamic classification. Eur Neurol 37: 13-17.

45. Fisher RS, Acevedo C, Arzimanoglou A, Bogacz A, Cross JH, Elger CE, et al (2014). ILAE official report: A practical clinical definition of epilepsy. Epilepsia 55: $475-482$

46. Fertig JB, Ryan ML, Falk DE, Litten RZ, Mattson ME, et al. (2012) A doubleblind, placebo-controlled trial assessing the efficacy of levetiracetam extendedrelease in very heavy drinking alcohol-dependent patients. Alcohol Clin Exp Res. 36: 1421-1430.

47. Clemens KJ, Vendruscolo LF (2008) Anxious to Drink: Gabapentin normalizes GABAergic transmission in the central amygdale and reduces symptoms of ethanol dependence. The Journal of Neuroscience 28: 9087-9089.

48. Bisaga A, Evans SM (2006) The acute effects of gabapentin in combination with alcohol in heavy drinkers. Drug Alcohol Depend 83: 25-32.

49. Rathlev NK, Ulrich A, Shieh TC, Callum MG, Bernstein E, et al. (2002) Etiology and weekly occurrence of alcohol-related seizures. Acad Emerg Med 9: 824828.

50. Jacobus J, Tapert SF (2013) Neurotoxic effects of alcohol in adolescence. Annu Rev Clin Psychol 9: 703-721.

51. Temkin NR (2009) Preventing and treating posttraumatic seizures: the human experience. Epilepsia 50 Suppl 2: 10-13.

52. Caputo F, Vignoli T, Leggio L, Addolorato G, Zoli G, et al. (2012) Alcoho use disorders in the elderly: a brief overview from epidemiology to treatment options. Exp Gerontol 47: 411-416.

53. Letizia M, Reinbolz M (2005) Identifying and managing acute alcohol withdrawal in the elderly. Geriatr Nurs 26: 176-183.

54. Maganti R, Gerber P, Drees C, Chung S (2008) Nonconvulsive status epilepticus. Epilepsy Behav 12: 572-586. 